\title{
Prediction of safe duration of hypothermic circulatory arrest by near-infrared spectroscopy
}

Takahiko Sakamoto, MDa

Shin'ichi Hatsuoka, MD

Ulrich A. Stock, MDa

Lennart F. Duebener, MDa

Hart G. W. Lidov, MD, PhD

Gregory L. Holmes, MDc

Jason S. Sperling, MDa

Mamoru Munakata, $\mathrm{MD}^{\mathrm{a}}$

Peter C. Laussen, MD $^{\mathrm{d}}$

Richard A. Jonas, MDa
From the Departments of Cardiac Surgery, ${ }^{\mathrm{a}}$ Pathology, ${ }^{\mathrm{b}}$ Neurology, ${ }^{\mathrm{c}}$ and Anesthesia and Intensive Care, ${ }^{\mathrm{d}}$ The Children's Hospital and Harvard Medical School, Boston, Mass.

This work was supported by National Institutes of Health Grant R01 HL600922.

Received for publication Oct 24, 2000; revisions requested Jan 26, 2001; revisions received Feb 6, 2001; accepted for publication Feb 19, 2001

Address for reprints: Richard A. Jonas, MD, Department of Cardiac Surgery, Children's Hospital, 300 Longwood Ave, Boston, MA 02115 (E-mail: richard.jonas@tch.harvard.edu).

J Thorac Cardiovasc Surg 2001;122:339-50

Copyright (ㅇ) 2001 by The American Association for Thoracic Surgery

0022-5223/2001 \$35.00+ $0 \quad \mathbf{1 2 / 1 / 1 1 5 2 4 2}$

doi:10.1067/mtc.2001.115242
Objective: Hypothermic circulatory arrest is widely used for adults with aortic arch disease as well as for children with congenital heart disease. At present, no method exists for monitoring safe duration of circulatory arrest. Near-infrared spectroscopy is a new technique for noninvasive monitoring of cerebral oxygenation and energy state. In the current study, the relationship between near-infrared spectroscopy data and neurologic outcome was evaluated in a survival piglet model with hypothermic circulatory arrest.

Methods: Thirty-six piglets $(9.36 \pm 0.16 \mathrm{~kg})$ underwent circulatory arrest under varying conditions with continuous monitoring by near-infrared spectroscopy (temperature $15^{\circ} \mathrm{C}$ or $25^{\circ} \mathrm{C}$, hematocrit value $20 \%$ or $30 \%$, circulatory arrest time 60,80 , or 100 minutes). Each setting included 3 animals. Neurologic recovery was evaluated daily by neurologic deficit score and overall performance category. Brain was fixed in situ on postoperative day 4 and examined by histologic score.

Results: Oxygenated hemoglobin signal declined to a plateau (nadir) during circulatory arrest. Time to nadir was significantly shorter with lower hematocrit value $(P$ $<.001)$ and higher temperature $(P<.01)$. Duration from reaching nadir until reperfusion ("oxygenated hemoglobin signal nadir time") was significantly related to histologic score $\left(r_{s}=0.826\right)$, neurologic deficit score $\left(r_{s}=0.717\right.$ on postoperative day $1 ; 0.716$ on postoperative day 4$)$, and overall performance category $\left(r_{s}=0.642\right.$ on postoperative day $1 ; 0.702$ on postoperative day 4$)(P<.001)$. All animals in which oxygenated hemoglobin signal nadir time was less than 25 minutes were free of behavioral or histologic evidence of brain injury.

Conclusion: Oxygenated hemoglobin signal nadir time determined by near-infrared spectroscopy monitoring is a useful predictor of safe duration of circulatory arrest. Safe duration of hypothermic circulatory arrest is strongly influenced by perfusate hematocrit value and temperature during circulatory arrest.

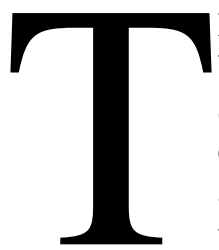

he technique of hypothermic circulatory arrest (HCA) continues to be widely used both for acquired cardiovascular disease (arch aneurysm repair, pulmonary embolectomy) and for congenital heart disease. Although many studies have made it clear that neurologic and developmental impairment can follow use of HCA in some patients under some conditions, ${ }^{1,2}$ the technique continues to be applied with no method for monitoring safe duration. Presently available methods of monitoring, for example, electroencephalography or jugular venous saturation, 
TABLE I. Experimental conditions 1

\begin{tabular}{|c|c|c|c|c|c|}
\hline Variable & Group 1 & Group 2 & Group 3 & Group 4 & ANOVA $(P)$ \\
\hline \multicolumn{6}{|l|}{ Body weight (kg) } \\
\hline Before operation & $9.00 \pm 0.36$ & $9.25 \pm 0.28$ & $9.51 \pm 0.37$ & $9.68 \pm 0.26$ & .47 \\
\hline POD 1 & $9.73 \pm 0.37$ & $10.60 \pm 0.21$ & $10.15 \pm 0.36$ & $11.48 \pm 0.27$ & $.0027^{*}$ \\
\hline$\%$ & $108.2 \pm 0.8$ & $114.9 \pm 1.2$ & $106.9 \pm 0.6$ & $118.7 \pm 1.7$ & $<.0001^{*}$ \\
\hline POD 4 & $8.84 \pm 0.35$ & $9.21 \pm 0.30$ & $9.81 \pm 0.41$ & $9.88 \pm 0.40$ & .19 \\
\hline$\%$ & $101.0 \pm 2.20$ & $99.5 \pm 1.0$ & $103.4 \pm 2.6$ & $101.5 \pm 1.7$ & .58 \\
\hline \multicolumn{6}{|l|}{ Hematocrit (\%) } \\
\hline Before CPB & $27.3 \pm 0.5$ & $28.8 \pm 1.4$ & $26.3 \pm 0.6$ & $27.0 \pm 0.7$ & .27 \\
\hline CPB prime & $32.2 \pm 0.9$ & $13.0 \pm 0.4$ & $32.0 \pm 0.9$ & $13.2 \pm 0.4$ & $<.0001^{*}$ \\
\hline On CPB & $33.2 \pm 0.6$ & $20.3 \pm 0.6$ & $33.2 \pm 0.7$ & $20.2 \pm 0.7$ & $<.0001^{*}$ \\
\hline Cooling $10 \mathrm{~min}$ & $33.6 \pm 0.6$ & $21.9 \pm 0.4$ & $32.8 \pm 0.7$ & $21.3 \pm 0.4$ & $<.0001^{*}$ \\
\hline $30 \mathrm{~min}$ & $33.6 \pm 0.8$ & $20.7 \pm 0.3$ & $33.1 \pm 0.8$ & $21.2 \pm 0.5$ & $<.0001^{*}$ \\
\hline Rewarming $10 \mathrm{~min}$ & $32.6 \pm 0.7$ & $23.2 \pm 0.6$ & $33.3 \pm 1.0$ & $25.9 \pm 1.6$ & $<.0001^{*}$ \\
\hline $30 \min$ & $34.4 \pm 0.7$ & $27.4 \pm 0.7$ & $34.2 \pm 0.7$ & $29.4 \pm 0.9$ & $<.0001^{*}$ \\
\hline 30 min off CPB & $29.2 \pm 1.0$ & $26.6 \pm 0.8$ & $28.4 \pm 0.5$ & $26.1 \pm 1.0$ & .04 \\
\hline POD 1 & $32.0 \pm 0.9$ & $29.2 \pm 0.9$ & $30.1 \pm 0.8$ & $29.4 \pm 0.4$ & .06 \\
\hline \multicolumn{6}{|l|}{ Temperature $\left({ }^{\circ} \mathrm{C}\right)$} \\
\hline Before CPB & $37.31 \pm 0.24$ & $36.99 \pm 0.36$ & $37.46 \pm 0.22$ & $37.43 \pm 0.21$ & .58 \\
\hline On CPB & $37.54 \pm 0.20$ & $37.09 \pm 0.42$ & $37.57 \pm 0.08$ & $37.51 \pm 0.14$ & .48 \\
\hline End of cooling & $13.33 \pm 0.13$ & $13.39 \pm 0.14$ & $22.94 \pm 0.08$ & $22.92 \pm 0.07$ & $<.0001^{*}$ \\
\hline End of HCA & $15.73 \pm 0.36$ & $16.62 \pm 0.39$ & $24.87 \pm 0.26$ & $25.40 \pm 0.19$ & $<.0001^{*}$ \\
\hline Rewarming 40 min & $37.32 \pm 0.19$ & $37.28 \pm 0.22$ & $37.72 \pm 0.11$ & $37.79 \pm 0.14$ & .09 \\
\hline $3 \mathrm{~h}$ & $36.42 \pm 0.40$ & $36.62 \pm 0.37$ & $37.10 \pm 0.33$ & $36.58 \pm 0.32$ & .57 \\
\hline POD 1 & $37.27 \pm 0.17$ & $37.50 \pm 0.14$ & $37.43 \pm 0.12$ & $37.46 \pm 0.18$ & .72 \\
\hline \multicolumn{6}{|c|}{ Mean arterial pressure (mm Hg) } \\
\hline Before CPB & $88.8 \pm 5.4$ & $87.3 \pm 4.1$ & $86.2 \pm 4.8$ & $97.9 \pm 4.8$ & .28 \\
\hline On CPB & $91.6 \pm 5.1$ & $62.1 \pm 7.8$ & $85.6 \pm 5.7$ & $52.8 \pm 7.0$ & $.0005^{*}$ \\
\hline Cooling $10 \mathrm{~min}$ & $69.1 \pm 5.2$ & $52.9 \pm 5.3$ & $94.2 \pm 4.7$ & $61.8 \pm 5.5$ & $<.0001^{*}$ \\
\hline $30 \mathrm{~min}$ & $56.9 \pm 5.7$ & $46.8 \pm 3.7$ & $88.6 \pm 6.5$ & $63.9 \pm 5.0$ & $<.0001^{*}$ \\
\hline Rewarming $10 \mathrm{~min}$ & $51.1 \pm 6.3$ & $43.8 \pm 4.9$ & $65.8 \pm 3.9$ & $67.5 \pm 4.6$ & $.0055^{*}$ \\
\hline $30 \min$ & $93.0 \pm 7.1$ & $101.4 \pm 5.5$ & $104.7 \pm 9.1$ & $92.4 \pm 7.6$ & .58 \\
\hline 30 min off CPB & $81.8 \pm 3.9$ & $80.3 \pm 3.3$ & $74.3 \pm 3.1$ & $78.9 \pm 6.2$ & .64 \\
\hline $3 \mathrm{~h}$ & $97.9 \pm 4.2$ & $95.9 \pm 4.3$ & $86.3 \pm 6.3$ & $97.2 \pm 4.3$ & .32 \\
\hline POD 1 & $91.0 \pm 3.7$ & $95.9 \pm 5.0$ & $99.7 \pm 3.6$ & $99.2 \pm 4.9$ & .48 \\
\hline
\end{tabular}

$C P B$, Cardiopulmonary bypass; $P O D$, postoperative day.

${ }^{*} P<.0083$ is statistically significant by analysis of variance and Bonferroni.

are unreliable or irrelevant under conditions of deep hypothermia, hemodilution, $\mathrm{pH}$ shifts, and circulatory arrest. ${ }^{3,4}$ Furthermore, widely different protocols are used to achieve HCA with considerable ongoing controversy regarding optimal $\mathrm{pH}$ strategy (pH-stat versus alpha-stat), optimal hematocrit value, and optimal temperature and flow conditions before HCA (cooling rate and duration).

Near-infrared spectroscopy (NIRS) is a relatively new technique for assessment of cerebral oxygenation..$^{5-7}$ Although serious questions remain regarding the validity of the cytochrome signal measured by NIRS, ${ }^{8,8 a}$ the information regarding hemoglobin oxygenation has been well validated.

The aim of the present study was to determine a safe duration of HCA as assessed by neurologic and histologic examination in a survival piglet model with HCA and to study the influence of hematocrit value and temperature on safe duration. All animals were monitored with NIRS with a view to deriving a NIRS parameter that was predictive of safe duration of HCA.

\section{Material and Method Experimental Preparation}

Details of the surgical instrumentation in the survival piglet model have been described elsewhere. ${ }^{9}$ Thirty-eight 5- or 6-week-old Yorkshire piglets, weighing $9.36 \pm 0.16 \mathrm{~kg}$, were sedated with intramuscular ketamine $(20 \mathrm{mg} / \mathrm{kg})$ and xylazine $(4 \mathrm{mg} / \mathrm{kg})$ and intubated with 5-mm cuffed endotracheal tubes. Each animal was ventilated at a peak inspiratory pressure of $20 \mathrm{~cm} \mathrm{H}_{2} \mathrm{O}$, an inspired oxygen fraction of 0.21 , and a rate of 12 to 15 breaths/min by means of a pressure-controlled ventilator (Healthdyne model 105; Healthdyne 

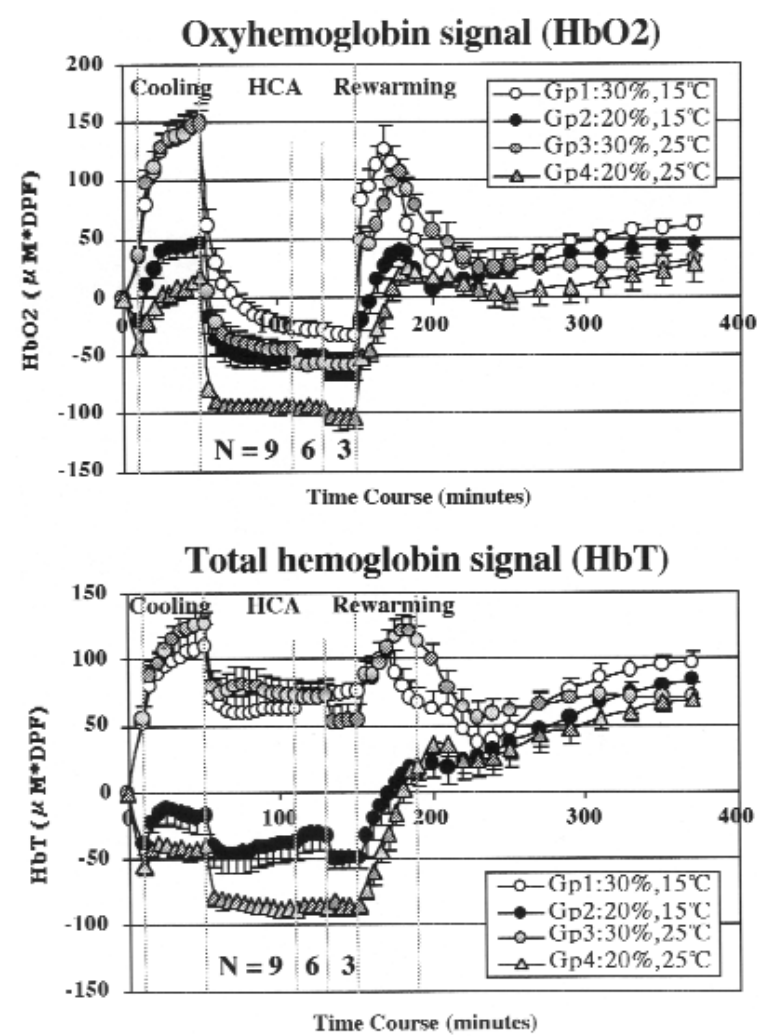
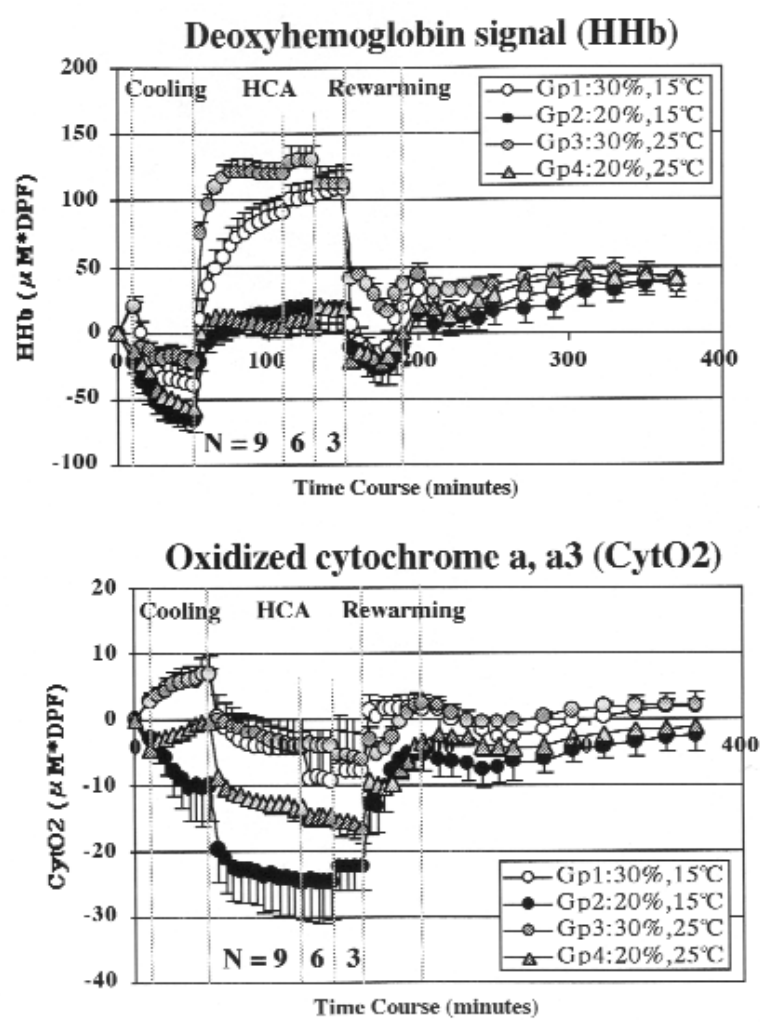

\section{Tissue Oxygenation Index (TOI)}

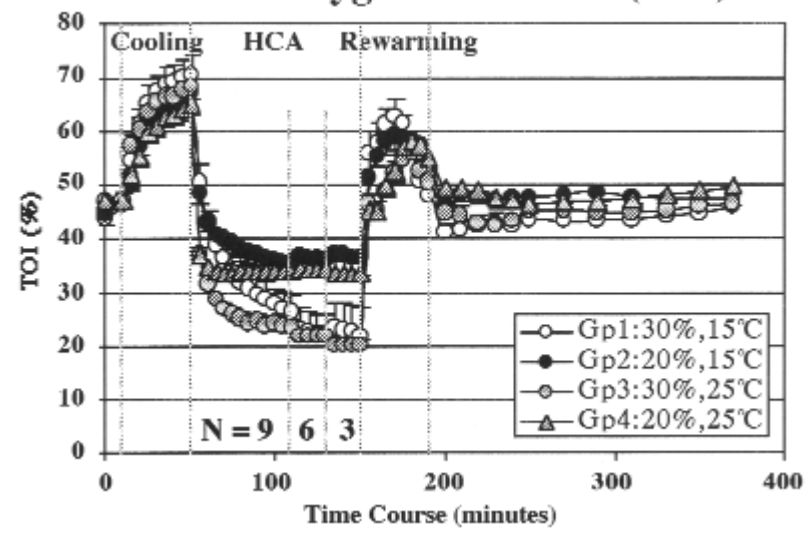

Figure 1. Results of NIRS. DPF, Differential path-length factor; $H C A$, hypothermic circulatory arrest; $G p$, group.

Technologies, Marietta, $\mathrm{Ga}$ ) to achieve a normal $\mathrm{pH}$ and $\mathrm{PaCO}_{2}$. A pair of fiberoptic optodes for NIRS was placed on the head over the frontal lobes, with an interoptode distance of $4.0 \mathrm{~cm}$. The total body water content was estimated by bioelectrical impedance with the use of a Weight Manager Analyzer (BIA-101Q; RJL Systems, Inc, Clinton Township, Mich). After an intravenous bolus injection of fentanyl $(50 \mu \mathrm{g} / \mathrm{kg})$ and pancuronium $(0.5 \mathrm{mg} / \mathrm{kg})$, anesthesia was maintained by a continuous infusion of fentanyl $\left(25 \mu \mathrm{g} \cdot \mathrm{kg}^{-1} \cdot \mathrm{h}^{-1}\right)$, midazolam $\left(0.2 \mathrm{mg} \cdot \mathrm{kg}^{-1} \cdot \mathrm{h}^{-1}\right)$ and pancuronium $\left(0.2 \mathrm{mg} \cdot \mathrm{kg}^{-1} \cdot \mathrm{h}^{-1}\right)$ throughout the entire experiment, except during the period of HCA.

All surgical procedures were performed under sterile conditions. For intraoperative monitoring and blood sampling, arteri- al and venous lines were placed in the left superficial femoral artery and right femoral vein, respectively. The right femoral artery was exposed for the cardiopulmonary bypass (CPB) arterial cannula, and a right anterolateral thoracotomy was performed in the third intercostal space to expose the right atrium for venous cannulation. After systemic heparinization (300 $\mathrm{IU} / \mathrm{kg}$ ), an $8 \mathrm{~F}$ arterial cannula (Medtronic BioMedicus, Eden Prairie, Minn) and a $28 \mathrm{~F}$ venous cannula (Research Medical, Inc, Midvale, Utah) were inserted into the right femoral artery and right atrial appendage, respectively.

All animals received humane care in compliance with the "Principles of Laboratory Animal Care" formulated by the 
TABLE II. Experimental conditions 2

\begin{tabular}{|c|c|c|c|c|c|}
\hline Variable & Group 1 & Group 2 & Group 3 & Group 4 & ANOVA (P) \\
\hline \multicolumn{6}{|c|}{ Percent total body water } \\
\hline Off CPB & $98.3 \pm 1.6$ & $114.6 \pm 3.7$ & $98.9 \pm 1.4$ & $113.4 \pm 2.5$ & $<.0001^{*}$ \\
\hline $1 \mathrm{~h}$ & $110.8 \pm 2.7$ & $126.3 \pm 3.2$ & $111.8 \pm 2.1$ & $129.4 \pm 2.8$ & $.0003^{*}$ \\
\hline $3 \mathrm{~h}$ & $118.7 \pm 3.1$ & $140.9 \pm 3.6$ & $118.5 \pm 2.2$ & $142.0 \pm 3.2$ & $<.0001^{*}$ \\
\hline POD 1 & $123.9 \pm 3.6$ & $148.8 \pm 3.0$ & $127.2 \pm 2.6$ & $152.4 \pm 4.6$ & $<.0001^{*}$ \\
\hline \multicolumn{6}{|l|}{ Osmolarity (Osm) } \\
\hline Before CPB & $270.6 \pm 1.3$ & $272.7 \pm 1.8$ & $270.9 \pm 1.2$ & $270.7 \pm 1.3$ & .69 \\
\hline On CPB & $278.1 \pm 1.0$ & $273.7 \pm 1.0$ & $275.3 \pm 1.4$ & $270.8 \pm 1.3$ & $.0010^{*}$ \\
\hline Cooling $30 \mathrm{~min}$ & $282.1 \pm 1.3$ & $275.9 \pm 0.9$ & $280.4 \pm 1.2$ & $275.9 \pm 1.0$ & $.0003^{*}$ \\
\hline Rewarming 30 min & $280.3 \pm 1.5$ & $277.8 \pm 1.0$ & $280.0 \pm 1.8$ & $278.7 \pm 1.2$ & .55 \\
\hline 30 min of CPB & $279.6 \pm 1.6$ & $278.9 \pm 1.3$ & $278.8 \pm 1.6$ & $278.9 \pm 1.3$ & .97 \\
\hline POD 1 & $278.8 \pm 1.9$ & $279.6 \pm 1.3$ & $279.7 \pm 1.3$ & $280.8 \pm 1.6$ & .85 \\
\hline \multicolumn{6}{|l|}{$\mathrm{SvO}_{2}(\%)$} \\
\hline On CPB & $77.23 \pm 1.43$ & $57.47 \pm 2.33$ & $73.81 \pm 2.07$ & $50.34 \pm 4.01$ & $<.0001^{*}$ \\
\hline Cooling $10 \mathrm{~min}$ & $90.76 \pm 0.70$ & $83.22 \pm 2.76$ & $83.97 \pm 1.65$ & $69.26 \pm 2.33$ & $<.0001^{*}$ \\
\hline $20 \mathrm{~min}$ & $97.61 \pm 0.51$ & $95.22 \pm 0.91$ & $91.01 \pm 0.93$ & $83.84 \pm 1.46$ & $<.0001^{*}$ \\
\hline $30 \mathrm{~min}$ & $99.69 \pm 0.08$ & $99.38 \pm 0.20$ & $94.28 \pm 0.73$ & $90.08 \pm 1.04$ & $<.0001^{*}$ \\
\hline Rewarming 10 min & $94.45 \pm 0.54$ & $93.90 \pm 1.15$ & $92.74 \pm 0.41$ & $91.26 \pm 1.13$ & .08 \\
\hline $20 \mathrm{~min}$ & $91.20 \pm 1.01$ & $87.23 \pm 1.23$ & $88.73 \pm 0.94$ & $88.28 \pm 1.31$ & .13 \\
\hline $30 \min$ & $85.86 \pm 1.52$ & $83.31 \pm 1.80$ & $85.90 \pm 0.79$ & $81.02 \pm 2.81$ & .23 \\
\hline \multicolumn{6}{|l|}{$\mathrm{pH} \dagger$} \\
\hline Before CPB & $7.484 \pm 0.015$ & $7.501 \pm 0.014$ & $7.482 \pm 0.016$ & $7.493 \pm 0.022$ & .86 \\
\hline Cooling $30 \mathrm{~min}$ & $7.441 \pm 0.017$ & $7.411 \pm 0.007$ & $7.451 \pm 0.013$ & $7.411 \pm 0.012$ & .07 \\
\hline Rewarming 30 min & $7.388 \pm 0.014$ & $7.409 \pm 0.012$ & $7.350 \pm 0.012$ & $7.332 \pm 0.014$ & $.0006^{*}$ \\
\hline $3 \mathrm{~h}$ & $7.490 \pm 0.013$ & $7.489 \pm 0.010$ & $7.450 \pm 0.017$ & $7.441 \pm 0.011$ & .02 \\
\hline \multicolumn{6}{|l|}{$\mathrm{PaCO}_{2}(\mathrm{~mm} \mathrm{Hg}) \dagger$} \\
\hline Before CPB & $39.20 \pm 1.62$ & $39.56 \pm 2.55$ & $39.29 \pm 2.09$ & $38.93 \pm 1.64$ & .99 \\
\hline Cooling $30 \mathrm{~min}$ & $44.16 \pm 2.06$ & $41.36 \pm 1.87$ & $46.10 \pm 1.32$ & $43.44 \pm 1.02$ & .25 \\
\hline Rewarming $30 \mathrm{~min}$ & $44.28 \pm 1.48$ & $41.86 \pm 1.10$ & $46.83 \pm 1.67$ & $45.96 \pm 1.87$ & .14 \\
\hline $3 \mathrm{~h}$ & $41.12 \pm 1.72$ & $40.80 \pm 1.72$ & $43.36 \pm 1.61$ & $43.66 \pm 1.76$ & .53 \\
\hline \multicolumn{6}{|l|}{$\mathrm{PaO}_{2}(\mathrm{~mm} \mathrm{Hg}) \dagger$} \\
\hline Before CPB & $91.66 \pm 4.74$ & $92.17 \pm 5.21$ & $93.07 \pm 4.15$ & $88.17 \pm 4.37$ & .89 \\
\hline Cooling $30 \mathrm{~min}$ & $636.28 \pm 20.62$ & $628.34 \pm 16.28$ & $577.47 \pm 12.49$ & $567.93 \pm 18.72$ & .02 \\
\hline Rewarming 30 min & $479.91 \pm 11.31$ & $478.14 \pm 8.99$ & $480.49 \pm 10.81$ & $485.86 \pm 15.89$ & .97 \\
\hline $3 \mathrm{~h}$ & $486.84 \pm 37.20$ & $483.91 \pm 14.28$ & $463.22 \pm 10.33$ & $437.43 \pm 23.03$ & .43 \\
\hline
\end{tabular}

$\mathrm{SVO}_{2}$, Mixed venous saturation; $\mathrm{CPB}$, cardiopulmonary bypass; $P O D$, postoperative day.

${ }^{*} P<.0083$ is statistically significant by analysis of variance and Bonferroni.

$\mathrm{tpH}, \mathrm{PaCO}_{2}$, and $\mathrm{PaO}_{2}$ are corrected for temperature.

National Society for Medical Research and the "Guide for the Care and Use of Laboratory Animals" prepared by the Institute of Laboratory Animal Resources, National Research Council, and published by the National Academy Press, revised 1996.

\section{Experimental Groups}

Hematocrit value. During the cooling phase a hematocrit value of either $20 \%$ or $30 \%$ was maintained.

Duration of HCA. A circulatory arrest time of 60,80 , or 100 minutes was used.

Temperature during HCA. An esophageal temperature of either $15^{\circ} \mathrm{C}$ or $25^{\circ} \mathrm{C}$ was used.
The experimental design included these three parameters with two or three possible values resulting in $2 \times 3 \times 2=12$ experimental settings. Each setting was performed in 3 piglets. In the group with a hematocrit value of $20 \%$, the CPB prime consisted of $400 \mathrm{~mL}$ of blood and $800 \mathrm{~mL}$ of crystalloid solution. The other group (hematocrit value of $30 \%$ ) was prepared with $1200 \mathrm{~mL}$ of whole-blood prime.

For ease of description, animals were considered in one of four groups with different hematocrit values and temperatures (group 1: hematocrit value $30 \%$, temperature $15^{\circ} \mathrm{C}$; group $2: 20 \%, 15^{\circ} \mathrm{C}$; group 3: $30 \%, 25^{\circ} \mathrm{C}$; and group 4: $20 \%, 25^{\circ} \mathrm{C}$ ) with three different durations of circulatory arrest $(60,80$, or 100 minutes) in each group. Operative conditions and intraoperative data including NIRS data were evaluated between the groups, and the relationship 
HbO2 decay curve

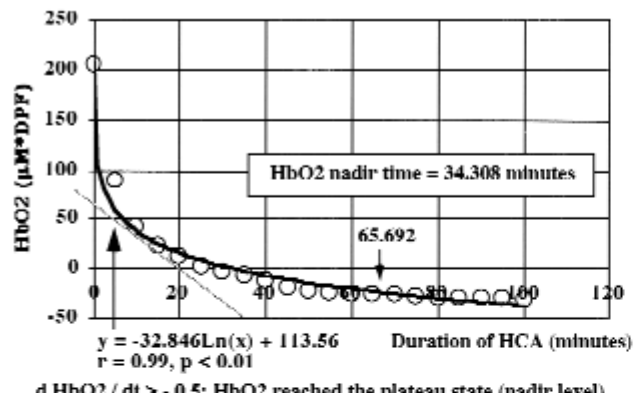

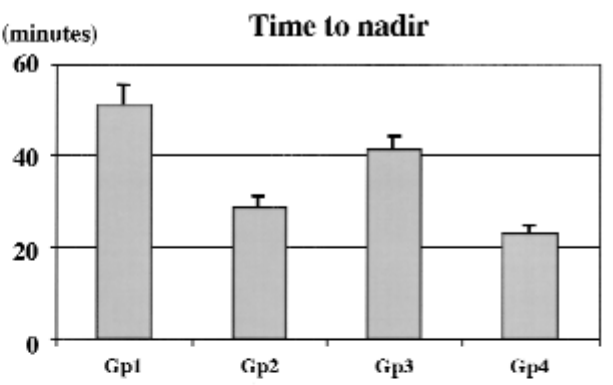
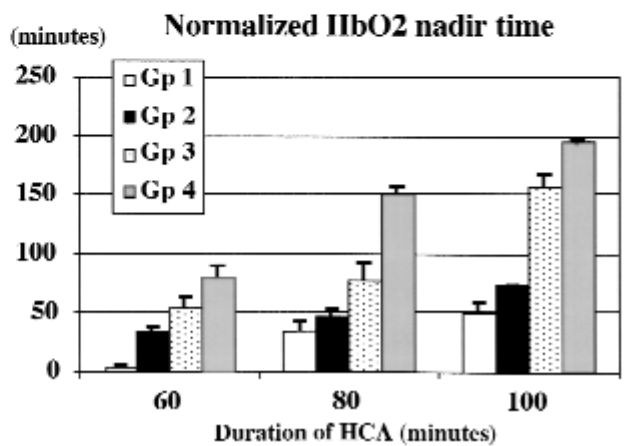

Figure 2. Oxyhemoglobin $\left(\mathrm{HbO}_{2}\right)$ decay curve and normalized $\mathrm{HbO}_{2}$ nadir time. During hypothermic circulatory arrest ( $\mathrm{HCA})$, the curve linear decrease in $\mathrm{HbO}_{2}$ signal $\left(\mathrm{HbO}_{2}\right.$ decay curve) can be described by a logarithmic function, $\mathrm{HbO}_{2}=\mathrm{a} \log (\mathrm{t})+\mathrm{b}, \mathrm{dHbO} / \mathrm{dt}=\mathrm{a} / \mathrm{t}$, where $t$ is the time after the onset of $\mathrm{HCA}$ and $a$ and $b$ are constants. We have defined that $\mathrm{HbO}_{2}$ signal reaches the plateau state (nadir value) when the slope of fitting curve, nameIy the differential coefficient, $\mathrm{dHbO}_{2} / \mathrm{dt}$, becomes more than $-0.5 . \mathrm{HbO}_{2}$ nadir time was normalized by using the temperature coefficient of 2.5 for the young piglet. Gp, Group.

between NIRS data and the neurologic outcome was examined comprehensively.

\section{CPB Technique}

The CPB circuit consisted of a roller pump, membrane oxygenator (Minimax; Medtronic), and sterile tubing, with a 40- $\mu \mathrm{m}$ arterial filter (Olson Medical Sales, Inc, Ashland, Mass). The prime was determined by the experimental protocol. Methylprednisolone (30 $\mathrm{mg} / \mathrm{kg})$, furosemide $(0.25 \mathrm{mg} / \mathrm{kg})$, sodium bicarbonate $(10 \mathrm{~mL})$, cefazolin sodium $(25 \mathrm{mg} / \mathrm{kg})$, fentanyl $(50 \mu \mathrm{g} / \mathrm{kg})$, and pancuronium $(0.5 \mathrm{mg} / \mathrm{kg})$ were added to the prime. Full bypass flow was set at $100 \mathrm{~mL} \cdot \mathrm{kg}^{-1} \cdot \mathrm{min}^{-1}$, and $\mathrm{pH}$-stat management was selected. $\mathrm{CPB}$ was started and the animals were perfused for 10 minutes at normothermia $\left(37^{\circ} \mathrm{C}\right)$. Animals were then cooled to an esophageal temperature of $13^{\circ} \mathrm{C}$ to $14^{\circ} \mathrm{C}$ or $23^{\circ} \mathrm{C}$ to $24^{\circ} \mathrm{C}$ over 40 minutes according to the experimental protocol. Ventilation was stopped after the establishment of $\mathrm{CPB}$. Each group underwent 60,80 , or 100 minutes of $\mathrm{HCA}$ at $14^{\circ} \mathrm{C}$ to $15^{\circ} \mathrm{C}$ or $24^{\circ} \mathrm{C}$ to $25^{\circ} \mathrm{C}$, according to the experimental protocol. Before reperfusion, methylprednisolone $(30 \mathrm{mg} / \mathrm{kg})$, furosemide $(0.25 \mathrm{mg} / \mathrm{kg})$, sodium bicarbonate $(10 \mathrm{~mL})$, and mannitol $(0.5 \mathrm{~g} / \mathrm{kg})$ were administered into the pump. Reperfusion was begun at a rate of $100 \mathrm{~mL} \mathrm{~kg}^{-1} \cdot \mathrm{min}^{-1}$, and each animal was warmed to $37^{\circ} \mathrm{C}$. The heart was defibrillated as necessary at an esophageal temperature of $30^{\circ} \mathrm{C}$. Fresh whole blood from a donor pig, drawn on the operative day, was transfused into the prime as required to increase the hematocrit value to at least $25 \%$ in all groups during rewarming. Ventilation (100\% oxygen) was started 10 minutes before weaning from CPB. After 40 minutes of rewarming, animals were weaned from $\mathrm{CPB}$ and the arterial and atrial cannulas were removed. Protamine $(5 \mathrm{mg} / \mathrm{kg})$ was administered intravenously after the animals were in a hemodynamically stable condition. The wound was closed in a sterile fashion.

\section{Postoperative Management}

Animals remained sedated and paralyzed and were mechanically ventilated and monitored continuously for 12 hours postoperatively, at which time chest tubes were removed and animals were weaned from ventilation and extubated. Neurologic and behavioral evaluations were performed at 24-hour intervals beginning on postoperative day (POD) 1. Neurologic scoring data were adapted from the neurologic deficit score and overall performance category, as described previously. ${ }^{10}$ On POD 4 , the brain was fixed with $4 \mathrm{~L}$ of $4 \%$ formaldehyde solution and the histologic assessment was done.

\section{Data Collection}

Body weight. Body weight was measured before the experiment and on PODs 1 and 4.

Total body water estimation by bioelectrical impedance. Percent change of total body water was measured at baseline and 

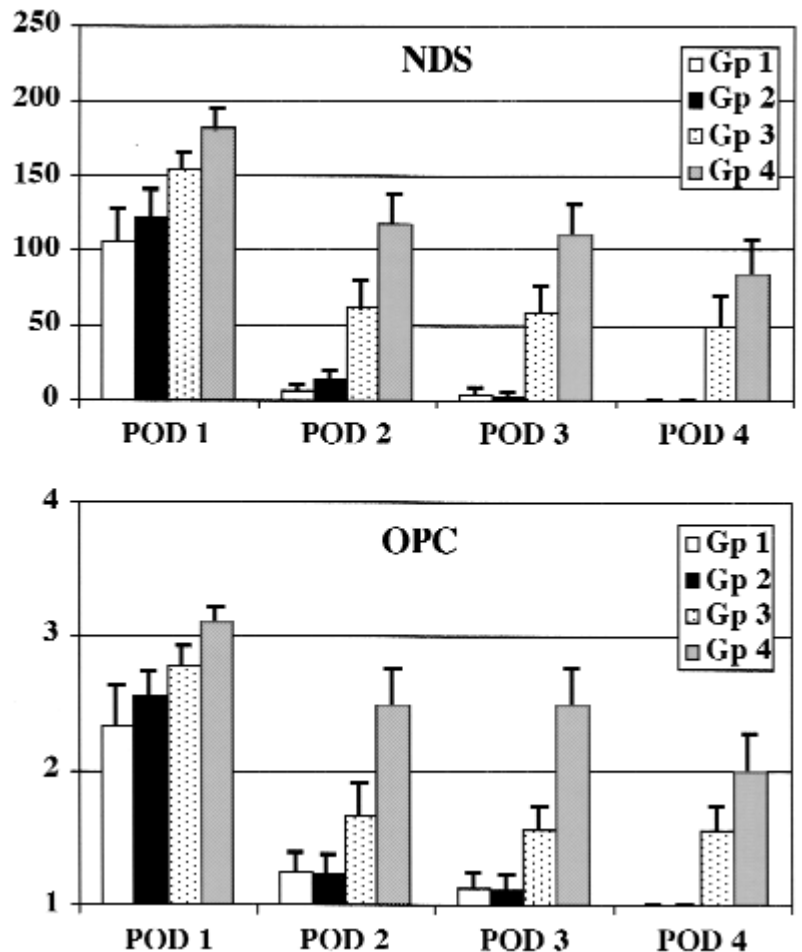

Figure 3. Results of neurologic and behavioral evaluations. NDS, Neurologic deficit score; OPC, overall performance category; $P O D$, postoperative day; $G p$, group.

repeated at weaning from $\mathrm{CPB}, 1$ hour and 3 hours after the procedure, and on POD 1.

Blood gas analyses. Arterial blood gas values, including electrolyte, glucose, and lactate concentrations, were measured at baseline, every 10 minutes during cooling and rewarming, and after the procedure as needed (NOVA 900; Nova Biomedical, Waltham, Mass).

NIRS. A pair of fiberoptic optodes was attached to the head of the animal with a probe holder after induction of anesthesia. The spacing of optodes was $4.0 \mathrm{~cm}$ in a coronal plane. These 2 optodes, a transmitter and a receiver of laser light of nearinfrared wavelength, were connected to NIRS (NIRO-300; Hamamatsu Photonics K.K., Hamamatsu City, Japan). This device calculated the relative concentration changes in oxygenated hemoglobin $\left(\mathrm{HbO}_{2}\right)$, deoxygenated hemoglobin, oxidized cytochrome a,a3, and tissue oxygenation index, which shows the ratio of tissue oxygenation and total hemoglobin. Data were recorded every 10 seconds after the induction of anesthesia and for 3 hours after weaning from CPB.

Biochemical analyses. Blood samples were drawn before CPB and on POD 1 to measure total protein, albumin, total bilirubin, aspartate transaminase, alanine transaminase, lactate dehydrogenase, creatinine kinase, alkaline phosphatase, blood urea nitrogen, and creatinine. Concentration of the brain ischemic marker S-100 protein was assessed at baseline, 30 minutes and 2 hours after weaning from $\mathrm{CPB}$, and on POD 1. The blood samples were immediately centrifuged, and the serum was stored at $-70^{\circ} \mathrm{C}$ for later measurement by a luminescence immunoassay (Sangtec LIA 100; AB Sangtec Medical, Bromma, Sweden). ${ }^{11}$
Neurologic and behavioral evaluations. Details have been described elsewhere. ${ }^{10}$ Neurologic deficit score (500: brain death; 0 : normal) and overall performance category (5: brain death; 1 : normal) were used for neurologic and behavioral evaluations and were carried out by one veterinarian who was blinded to the experimental protocol.

Histologic assessment. Details have been described elsewhere. ${ }^{12}$ Histologic evaluation (5: necrosis; 0: normal) was performed by a neuropathologist in a blinded fashion.

\section{Statistical Analysis}

All results were expressed as mean \pm standard error of the mean and analyzed by a statistical analysis software package (StatView 4.5; SAS Institute, Inc, Cary, NC). Analysis of variance and the Bonferroni test were used to analyze the data between the groups. Nonparametric correlation coefficients according to Spearman were used for the correlation analyses of the NIRS data with the neurologic deficit score, overall performance category, and histologic score.

\section{Results}

\section{Experimental Conditions}

The experimental conditions for each group are shown in Tables 1 and 2 . There were no significant differences between the groups in body weight and esophageal temperature before the operation and in $\mathrm{pH}, \mathrm{PaO}_{2}$, and $\mathrm{PaCO}_{2}$ during the experiments. On the other hand, there was a 

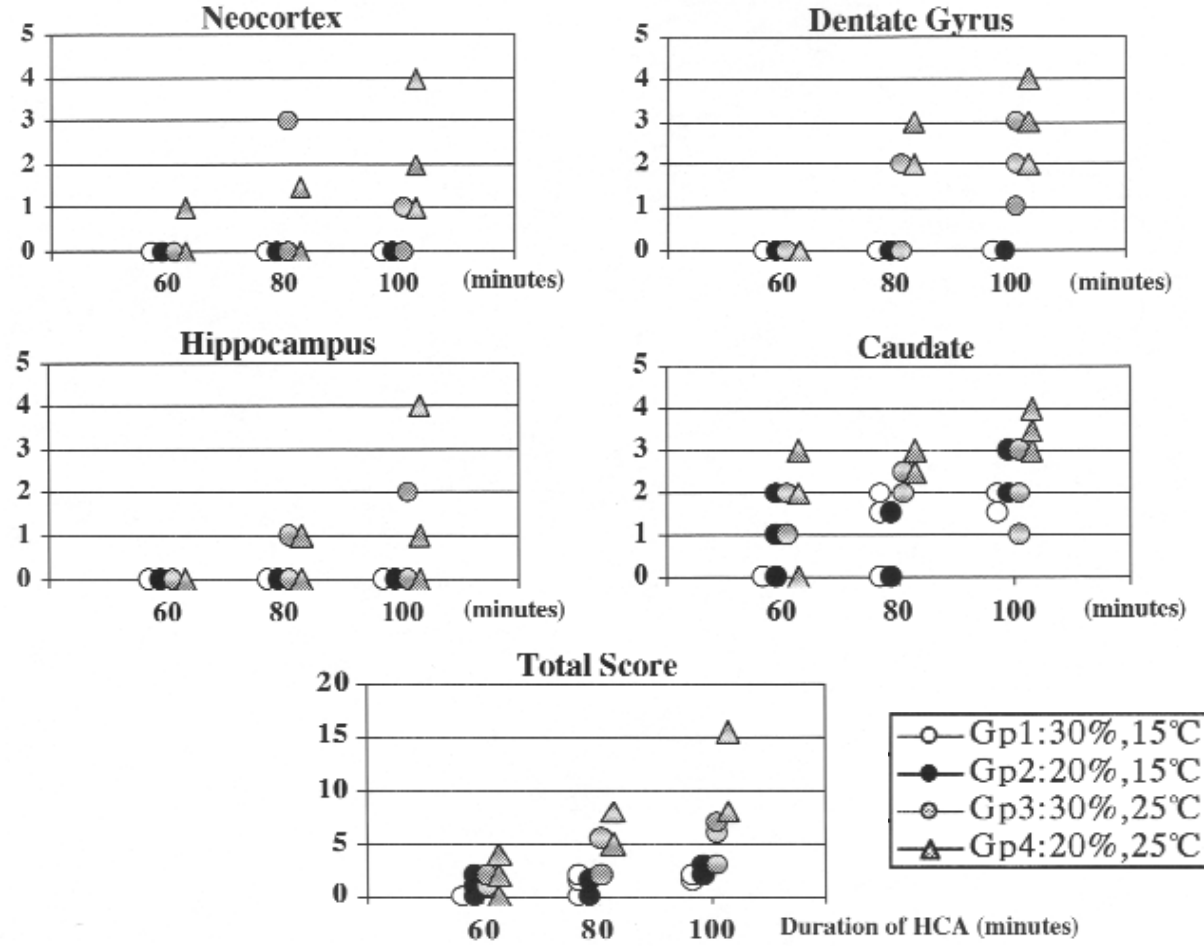

Figure 4. Results of histologic scores. HCA, Hypothermic circulatory arrest.

difference in mixed venous oxygen saturation $\left(\mathrm{SvO}_{2}\right)$ during the cooling phase $(P<.0001)$. During the cooling phase, hematocrit value and temperature were set according to protocol, but no differences were noted between the groups after rewarming and on POD 1. Mean arterial pressure was significantly higher in group $3\left(30 \% / 25^{\circ} \mathrm{C}\right)$ during the cooling phase $(P<.0001)$, but no significant differences existed between the groups after rewarming and on POD 1. Also, osmolarity was significantly higher in groups $1\left(30 \% / 15^{\circ} \mathrm{C}\right)$ and $3\left(30 \% / 25^{\circ} \mathrm{C}\right)$ during the cooling phase $(P=.0003)$.

\section{Operative Results}

Two animals died; one had ventricular fibrillation 9 hours after weaning from $\mathrm{CPB}$ and the other had a severe tension pneumothorax on POD 1. All data from these animals were excluded from analysis. Two animals (hematocrit values of $30 \%$ and $20 \%$, temperatures of $15^{\circ} \mathrm{C}$ and $25^{\circ} \mathrm{C}$, and $\mathrm{HCA}$ durations of 100 minutes each), in which extremely low cerebral oxygenation was detected by NIRS, died of severe brain damage with seizures at 5 to 6 hours after extubation on POD 1. Another animal $\left(20 \%, 25^{\circ} \mathrm{C}, 80\right.$ minutes $)$ died of brain herniation, which was confirmed by brain fixation immediately after death on POD 4. Data from these animals were included in the analysis, although histologic information was not obtained in 2 of them.

\section{Body Weight Change}

The changes in percentage body weight were significantly different between the groups on POD 1. The groups assigned to higher hematocrit values gained less weight. However, body weights of almost all animals returned to the preoperative level and there were no significant differences on POD 4 (Table 1).

\section{Total Body Water Content}

Calculated percentage of total body water content showed marked edema in groups $2\left(20 \% / 15^{\circ} \mathrm{C}\right)$ and $4\left(20 \% / 25^{\circ} \mathrm{C}\right)$ after weaning from CPB (Table 2).

\section{NIRS (Figures 1 and 2)}

The $\mathrm{HbO}_{2}$ signal increased significantly during the cooling phase in all groups. In groups $1\left(30 \% / 15^{\circ} \mathrm{C}\right)$ and 3 $\left(30 \% / 25^{\circ} \mathrm{C}\right)$, the $\mathrm{HbO}_{2}$ signal continued to increase during the entire cooling phase, whereas the $\mathrm{HbO}_{2}$ signal reached a plateau after about 20 minutes in groups $2\left(20 \% / 15^{\circ} \mathrm{C}\right)$ and 4 $\left(20 \% / 25^{\circ} \mathrm{C}\right)$. Total hemoglobin showed almost the same pattern as $\mathrm{HbO}_{2}$ during the cooling phase. On the other hand, tissue oxygenation index demonstrated an increase without plateau in all groups, and there was significant difference between groups $1\left(30 \% / 15^{\circ} \mathrm{C}\right)$ and $4\left(20 \% / 25^{\circ} \mathrm{C}\right)$ at the end of cooling. From the onset of HCA, there was a decline in $\mathrm{HbO}_{2}$, oxidized cytochrome a,a3, and tissue oxygenation index and a reciprocal increase in deoxygenated hemoglobin. 
TABLE III. Spearman's correlation coefficients for NIRS data and neurologic and behavioral evaluations

\begin{tabular}{|c|c|c|c|c|c|}
\hline NIRS data variable & Aggregate function & NDS 1 & OPC 1 & NDS 4 & OPC 4 \\
\hline \multirow{2}{*}{$\mathrm{HbO}_{2}(\mu \mathrm{mol} / \mathrm{L} \cdot \mathrm{DPF})$} & Maximum & -0.315 & $-0.373^{*}$ & -0.197 & -0.178 \\
\hline & Minimum & $-0.469 \dagger$ & $-0.470 \dagger$ & $-0.537 \dagger$ & $-0.545 \dagger$ \\
\hline \multirow[t]{2}{*}{$\mathrm{HHb}(\mu \mathrm{mol} / \mathrm{L} \cdot \mathrm{DPF})$} & Maximum & -0.174 & -0.225 & -0.041 & -0.044 \\
\hline & Minimum & -0.047 & -0.068 & 0.132 & 0.177 \\
\hline \multirow[t]{2}{*}{$\mathrm{HbT}(\mu \mathrm{mol} / \mathrm{L} \cdot \mathrm{DPF})$} & Maximum & -0.271 & -0.333 & -0.104 & -0.090 \\
\hline & Minimum & -0.281 & -0.313 & -0.239 & -0.243 \\
\hline \multirow[t]{2}{*}{$\mathrm{CytO}_{2}(\mu \mathrm{mol} / \mathrm{L} \cdot \mathrm{DPF})$} & Maximum & -0.058 & -0.187 & 0.052 & 0.052 \\
\hline & Minimum & 0.001 & -0.118 & 0.016 & 0.027 \\
\hline \multirow[t]{3}{*}{ TOI (\%) } & Maximum & $-0.364^{*}$ & $-0.377^{*}$ & 0.033 & 0.064 \\
\hline & Minimum & -0.044 & 0.061 & -0.037 & -0.015 \\
\hline & HCA 5 min & $-0.480 \dagger$ & $-0.452 \dagger$ & $-0.504 \dagger$ & $-0.504 \dagger$ \\
\hline \multicolumn{2}{|c|}{ Normalized $\mathrm{HbO}_{2}$ nadir time (min) } & $0.717 \ddagger$ & $0.642 \ddagger$ & $0.716 \ddagger$ & $0.702 \ddagger$ \\
\hline
\end{tabular}

NDS 1(4), Neurologic deficit score at 1(4) day(s) postoperatively; OPC 1(4), overall performance category at 1(4) day(s) postoperatively; $\mathrm{HbO}_{2}$, oxygenated

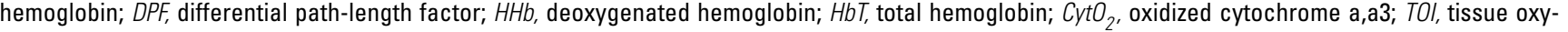
genation index.

${ }^{*} P<.05$.

$\dagger P<.01$.

$\ddagger P<.0001$

In groups $2\left(20 \% / 15^{\circ} \mathrm{C}\right)$ and $4\left(20 \% / 25^{\circ} \mathrm{C}\right), \mathrm{HbO}_{2}$ declined to a plateau within approximately 30 minutes, whereas in groups $1\left(30 \% / 15^{\circ} \mathrm{C}\right)$ and $3\left(30 \% / 25^{\circ} \mathrm{C}\right)$, the plateau occurred after approximately 60 and 40 minutes, respectively. During $\mathrm{HCA}$, the decrease in $\mathrm{HbO}_{2}$ signal $\left(\mathrm{HbO}_{2}\right.$ decay curve $)$ can be described by a logarithmic function,

$$
\mathrm{HbO}_{2}=\mathrm{a} \log (\mathrm{t})+\mathrm{b}, \mathrm{dHbO}_{2} / \mathrm{dt}=\mathrm{a} / \mathrm{t}
$$

where $t$ is the time after the onset of HCA and $a$ and $b$ are constants. We have defined that $\mathrm{HbO}_{2}$ signal reaches the plateau state (nadir value) when the slope of the fitting curve, namely the differential coefficient $\left(\mathrm{dHbO}_{2} / \mathrm{dt}\right)$, becomes more than -0.5 . Time to reach plateau was calculated in each case. In groups $2\left(20 \% / 15^{\circ} \mathrm{C}\right)$ and $4\left(20 \% / 25^{\circ} \mathrm{C}\right)$, this was $28.7 \pm 2.4$ minutes and $23.1 \pm 1.7$ minutes, whereas in groups $1\left(30 \% / 15^{\circ} \mathrm{C}\right)$ and $3\left(30 \% / 25^{\circ} \mathrm{C}\right)$, this time was 51.3 \pm 4.1 minutes and $41.4 \pm 2.9$ minutes. Analysis of variance revealed a highly significant effect of hematocrit value $(P<$ $.001)$ and temperature $(P<.01)$. Bonferroni $\mathrm{t}$ test indicated that group $1\left(30 \% / 15^{\circ} \mathrm{C}\right)$ is longer than group $2\left(20 \% / 15^{\circ} \mathrm{C}\right)$ and group $4\left(20 \% / 25^{\circ} \mathrm{C}\right)(P<.001$ for each), and group 3 $\left(30 \% / 25^{\circ} \mathrm{C}\right)$ is longer than group $2\left(20 \% / 15^{\circ} \mathrm{C}\right)(P=.02)$ and group $4\left(20 \% / 25^{\circ} \mathrm{C}\right)(P<.001)$. No differences were detected between group $1\left(30 \% / 15^{\circ} \mathrm{C}\right)$ and group $3\left(30 \% / 25^{\circ} \mathrm{C}\right)(P$ $=.13)$ or between group $2\left(20 \% / 15^{\circ} \mathrm{C}\right)$ and group 4 $\left(20 \% / 25^{\circ} \mathrm{C}\right)(P=.98)$. The duration from reaching nadir until reperfusion was calculated in each case and was termed " $\mathrm{HbO}_{2}$ nadir time."

\section{Enzymes}

No significant difference existed between the groups. The increase of aspartate transaminase and alkaline transami- nase levels tended to be larger when the hematocrit value was lower and the HCA was longer. However, ischemic damage to the whole body as determined by enzyme changes was considered mild on the whole. The S-100 protein peaked at 30 minutes after CPB and decreased to normal on POD 1. However, there were no differences between the groups (data not shown).

\section{Neurologic and Behavioral Evaluations (Figure 3)}

The neurologic deficit score and overall performance category showed relatively rapid recovery in all groups. Most animals assigned to $15^{\circ} \mathrm{C}$ recovered and showed normal performance without neurologic deficit by PODs 3 and 4 . However, the animals assigned to $25^{\circ} \mathrm{C}$ with longer durations of HCA did not recover to normal.

\section{Histological Assessment (Figure 4)}

Neuropathologic injury was evaluated in the same manner as in previous studies. ${ }^{12}$ Evidence of hypoxicischemic injury was indicated by the presence of hypereosinophilic shrunken neurons with karyorrhectic nuclei. Damage scores for all regions were summed and shown as total score. Histologic damage was found predominantly in the caudate nucleus. All 3 animals with the higher hematocrit value (30\%), the lower temperature $\left(15^{\circ} \mathrm{C}\right)$, and the shortest HCA (60 minutes) showed no brain damage. On the other hand, all animals with the lower hematocrit value $(20 \%)$, the higher temperature $\left(25^{\circ} \mathrm{C}\right)$, and the longest HCA (100 minutes) demonstrated severe brain damage. There was a tendency for worse score when hematocrit value was lower, temperature was higher, and HCA was longer. 

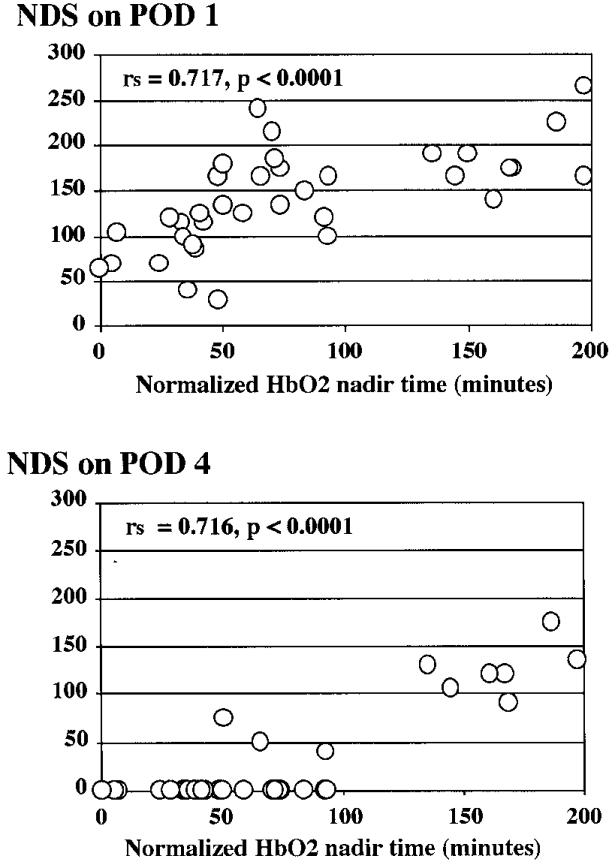
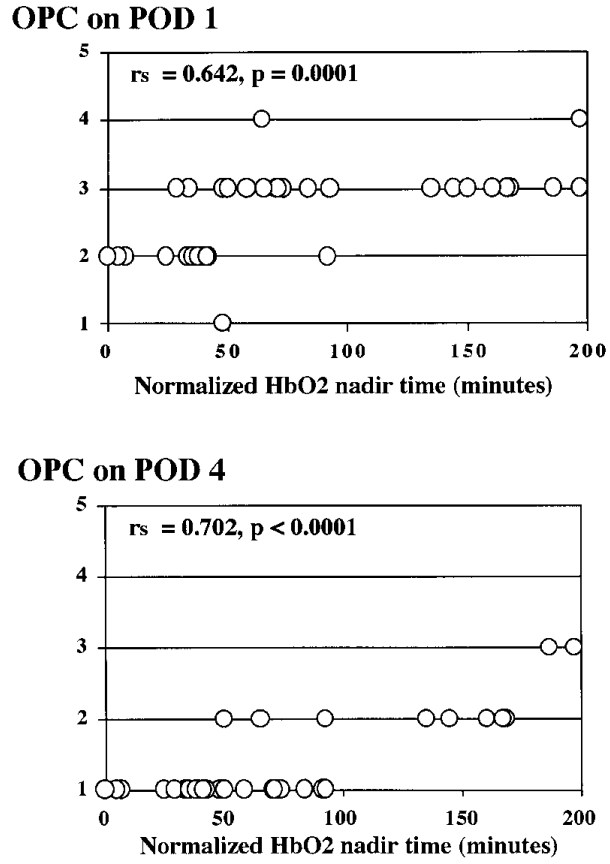

Figure 5. Correlation figures between near-infrared spectroscopy (NIRS) data (normalized $\mathrm{HbO}_{2}$ nadir time) and neurologic behavioral evaluations. NDS, Neurologic deficit score; OPC, overall performance category; POD, postoperative day.

\section{Correlation Between NIRS Data and Neurologic Outcome (Tables 3 and 4 and Figures 5 and 6)}

To establish a useful monitoring system, we evaluated which NIRS data predicted the neurologic outcomes shown by neurologic deficit score, overall performance category, and histologic score. Because the metabolic rate is different between the different temperatures, we normalized the $\mathrm{HbO}_{2}$ nadir time by using an estimated temperature coefficient of 2.5 for the young piglet. $^{12}$ Normalized $\mathrm{HbO}_{2}$ nadir time was calculated as shown in Figure 2. Minimal $\mathrm{HbO}_{2}$, tissue oxygenation index at 5 minutes after the beginning of HCA, and normalized $\mathrm{HbO}_{2}$ nadir time were indices that were found to predict neurologic outcome. In particular, normalized $\mathrm{HbO}_{2}$ nadir time was significantly related to histologic score $\left(r_{s}=\right.$ 0.826), neurologic deficit score $\left(r_{s}=0.717\right.$ on POD 1 , 0.716 on POD 4$)$, and overall performance category $\left(r_{s}=\right.$ 0.642 on POD $1,0.702$ on POD 4$)(P<.001)$. All animals in which $\mathrm{HbO}_{2}$ nadir time was less than 25 minutes were free of behavioral or histologic evidence of brain injuries, which were shown as neurologic deficit score more than 0 on POD 4, overall performance category more than 1 on POD 4, and histologic score more than 0.

\section{Discussion}

This study has demonstrated that increasing duration of HCA is associated with worse neurologic and histologic outcome in the young piglet. Furthermore, the degree of injury is exacerbated by use of a lower perfusate hematocrit value $(20 \%$ vs $30 \%)$ and/or a higher temperature $\left(25^{\circ} \mathrm{C}\right.$ vs $15^{\circ} \mathrm{C}$ ). There is ongoing oxygen extraction during the early phase of HCA that can be monitored by NIRS. A longer duration of minimal or absent oxygen extraction $\left(\mathrm{HbO}_{2}\right.$ nadir time) predicts worse neurologic and histologic outcome. This NIRS-derived parameter could be useful as a monitoring method to determine safe duration of HCA irrespective of the perfusion methods used to achieve HCA.

This study builds on two previous studies from our laboratory in which we examined the influence of hematocrit value on outcome after deep HCA. ${ }^{9,14}$ In the first study, we measured cerebral high-energy phosphates with magnetic resonance spectroscopy. We found that use of a low hematocrit value (10\%) was associated with a marked decline in cerebral phosphocreatinine during cooling before deep HCA and delayed recovery of adenosine triphosphate and creatine phosphate after deep HCA relative to a hematocrit value of $20 \%$ or $30 \%$. In the second study, we independently manipulated hematocrit value and oncotic pressure. These two studies used a model with daily neurologic observations by a blinded veterinarian as well as histologic assessment by a blinded neuropathologist. Also, NIRS monitoring was undertaken simultaneously as well as magnetic resonance spectroscopy. However, these studies used only one duration of HCA, that is, 60 minutes of deep hypothermia at $15^{\circ} \mathrm{C}$, and this resulted in 


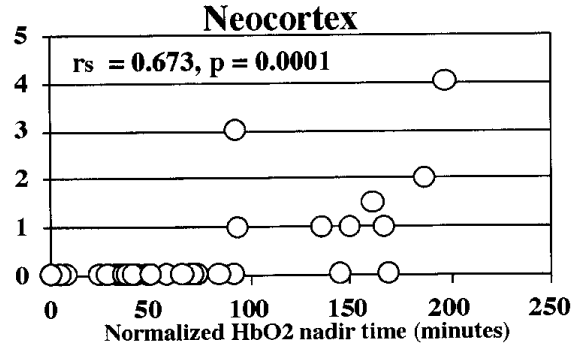

Hippocampus

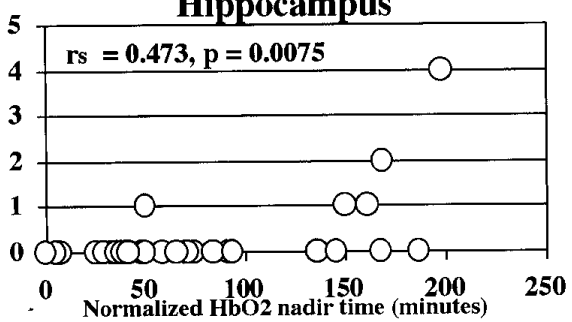

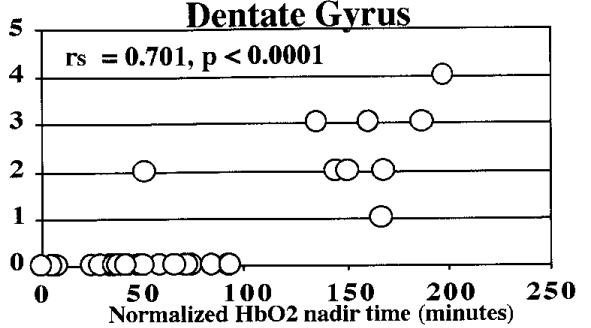

Caudate Nucleus

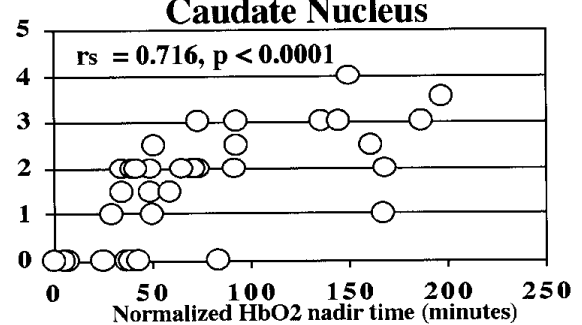

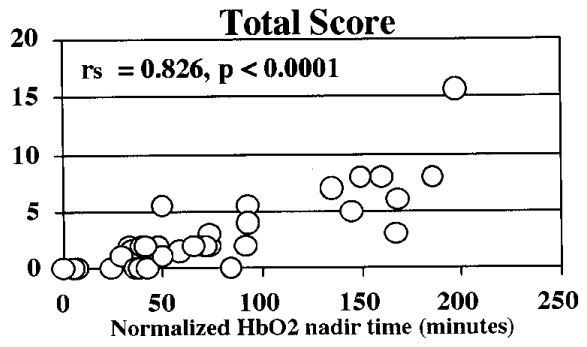

Figure 6. Correlation figures between near infrared spectroscopy (NIRS) data (normalized $\mathrm{HbO}_{2}$ nadir time) and histologic scores.

relatively minor damage as noted by the normal neurologic examinations 4 days postoperatively as well as fairly minor histologic changes. Nevertheless, these two studies did confirm that a hematocrit value of $30 \%$ resulted in a better outcome than a hematocrit value of $20 \% .{ }^{14}$

In the present study, three different durations of HCA and two different temperatures were used. As might seem intuitively obvious and as previously reported by others, ${ }^{13,15-19}$ a longer duration of HCA was associated with a higher probability of neurologic and histologic injury. However, it is clear that the amount of injury was also strongly influenced by the conditions of HCA, specifically the hematocrit value of the perfusate and temperature (Figures 3 and 4). Analysis of the NIRS data provides a compelling rationale for the role of hematocrit value and temperature in influencing outcome.

Figure 1 illustrates the changes in oxygenated and deoxygenated hemoglobin during HCA. It can be seen that with a hematocrit value of $30 \%$ there is a state of hyperoxygenation during cooling before HCA. Presumably this represents not only the hyperoxygenated state of the arterial perfusate (inspired oxygen fraction in the oxygenator was 1.0) but also the fall in cerebral metabolic rate as brain temperature decreases ( $70 \%$ of the NIRS hemoglobin signal is derived from cerebral venous blood). There is significantly less hyperoxygenation with a hematocrit value of $20 \%$ versus $30 \%$ during the cooling phase. After the onset of $\mathrm{HCA}$ there is an immediate and ongoing fall in $\mathrm{HbO}_{2}$ and a rise in deoxygenated hemoglobin in all groups. Furthermore, there are important differences in the shape of these 4 curves, which are influenced by both hematocrit and temperature. During the early period of HCA, groups 3 $\left(30 \% / 25^{\circ} \mathrm{C}\right)$ and $4\left(20 \% / 25^{\circ} \mathrm{C}\right)$, with higher temperature, showed a more rapid decrease in $\mathrm{HbO}_{2}$ and increase in deoxygenated hemoglobin than groups $1\left(30 \% / 15^{\circ} \mathrm{C}\right)$ and 2 $\left(20 \% / 15^{\circ} \mathrm{C}\right)$, suggesting inadequate metabolic suppression. Groups $2\left(20 \% / 15^{\circ} \mathrm{C}\right)$ and $4\left(20 \% / 25^{\circ} \mathrm{C}\right)$, with lower hematocrit value, reached a point of inflection after $28.7 \pm 2.4$ and $23.1 \pm 1.7$ minutes, respectively, beyond which point there was minimal further decline in intracranial oxygenated hemoglobin. Groups $1\left(30 \% / 15^{\circ} \mathrm{C}\right)$ and $3\left(30 \% / 25^{\circ} \mathrm{C}\right)$, with higher hematocrit values, did not reach this point of inflection until $51.3 \pm 4.1$ and $41.4 \pm 2.9$ minutes after the onset of HCA. If one relates the duration of HCA beyond this point of inflection (" $\mathrm{HbO}_{2}$ nadir time," which should be normalized to account for the difference of temperature 
TABLE IV. Spearman's correlation coefficients for NIRS data and histologic score

\begin{tabular}{|c|c|c|c|c|c|c|}
\hline NIRS data variable & $\begin{array}{c}\text { Aggregate } \\
\text { function }\end{array}$ & Neocortex & $\begin{array}{c}\text { Dentate } \\
\text { gyrus }\end{array}$ & Hippocampus & $\begin{array}{l}\text { Caudate } \\
\text { nucleus }\end{array}$ & $\begin{array}{l}\text { Total } \\
\text { score }\end{array}$ \\
\hline \multirow[t]{2}{*}{$\mathrm{HbO}_{2}(\mu \mathrm{mol} / \mathrm{L} \cdot \mathrm{DPF})$} & Maximum & -0.376 & -0.264 & -0.167 & -0.270 & -0.254 \\
\hline & Minimum & $-0.420^{*}$ & $-0.485 \dagger$ & -0.319 & $-0.430^{*}$ & $-0.484 \dagger$ \\
\hline \multirow[t]{2}{*}{$\mathrm{HHb}(\mu \mathrm{mol} / \mathrm{L} \cdot \mathrm{DPF})$} & Maximum & -0.200 & -0.081 & -0.121 & -0.179 & -0.101 \\
\hline & Minimum & 0.023 & 0.091 & 0.066 & -0.153 & 0.017 \\
\hline \multirow[t]{2}{*}{$\mathrm{HbT}(\mu \mathrm{mol} / \mathrm{L} \cdot \mathrm{DPF})$} & Maximum & -0.217 & -0.164 & -0.122 & -0.269 & -0.205 \\
\hline & Minimum & -0.319 & -0.254 & -0.177 & -0.266 & -0.227 \\
\hline \multirow[t]{2}{*}{$\mathrm{CytO}_{2}(\mu \mathrm{mol} / \mathrm{L} \cdot \mathrm{DPF})$} & Maximum & -0.071 & 0.022 & -0.032 & -0.159 & -0.065 \\
\hline & Minimum & -0.157 & -0.002 & 0.036 & -0.123 & -0.059 \\
\hline \multirow[t]{3}{*}{ TOI (\%) } & Maximum & -0.149 & -0.053 & -0.164 & -0.210 & -0.203 \\
\hline & Minimum & 0.022 & -0.023 & 0.099 & -0.124 & -0.182 \\
\hline & HCA 5 min & $-0.590 \dagger$ & $-0.421^{*}$ & -0.248 & $-0.541 \dagger$ & $-0.594 \dagger$ \\
\hline \multicolumn{2}{|c|}{ Normalized $\mathrm{HbO}_{2}$ nadir time (min) } & $0.673 \ddagger$ & $0.701 \ddagger$ & $0.473^{\dagger}$ & $0.716 \ddagger$ & $0.826 \ddagger$ \\
\hline
\end{tabular}

NIRS, Near infrared spectroscopy; $\mathrm{HbO}_{2}$, oxygenated hemoglobin; $\mathrm{DPF}$, differential path-length factor; $H H b$, deoxygenated hemoglobin; $H b T$, total hemoglobin; $\mathrm{CytO}_{2}$, oxidized cytochrome a,a3; $\mathrm{TO}$, tissue oxygenation index.

${ }^{*} P<.05$.

$\dagger P<.01$.

$\ddagger P<.0001$.

and therefore different metabolic rate) to neurologic and histologic outcome (Figures 5 and 6), it is clear that this NIRS-derived parameter is a powerful predictor of neurologic injury.

The mechanism by which $\mathrm{HbO}_{2}$ nadir time predicts outcome is unknown. However, it would seem reasonable to speculate that the gradual fall in $\mathrm{HbO}_{2}$ during $\mathrm{HCA}$ reflects ongoing oxygen metabolism in cerebral neurons and astroglia. Many previous reports have confirmed that cerebral metabolism is not abolished during HCA. ${ }^{13,19}$ Deep hypothermia should be able to suppress but cannot stop brain metabolism. The finding that $\mathrm{HbO}_{2}$ reaches a nadir value suggests that the available cerebral $\mathrm{HbO}_{2}$ is depleted at this point. ${ }^{20}$ When all oxygen has been extracted from both the arterial and venous phases within the brain, anaerobic metabolism ensues. If sufficiently prolonged, the resulting acidosis can result in neuronal and endothelial injury. Therefore, $\mathrm{HbO}_{2}$ nadir time could be considered to be a critical period when cerebral neurons cannot use oxygen but cerebral metabolism is still ongoing. Interestingly, Figure 1 suggests that during the reperfusion phase there is significantly greater cerebral flow with a higher hematocrit value regardless of the temperature during circulatory arrest. We have made similar direct observations in the cerebral microcirculation using the technique of intravital microscopy (unpublished data).

In our previous reports in which we used NIRS, we focused considerable attention on the potential value of the cytochrome signal. ${ }^{21}$ Binding of oxygen to hemoglobin is markedly altered under the conditions of bypass used before circulatory arrest and complicates the interpretation of the hemoglobin oxygenation status (in the same way that $\mathrm{SvO}_{2}$ data can be misleading during bypass with hypothermia and alkalosis when there is a marked shift to the left of the oxyhemoglobin dissociation curve). However, recent studies from our laboratory using sodium cyanide to dissociate cytochrome from hemoglobin have failed to validate the cytochrome signal and in fact have demonstrated a marked degree of crosstalk between hematocrit and cytochrome. ${ }^{8 a}$ Efforts are presently underway to derive an algorithm that will correct the cytochrome signal for variations in hematocrit such as occur under the changing conditions of CPB. On the other hand, the NIRO-300 device calculates tissue oxygenation index that is influenced by tissue saturation as well as the hematocrit changes. ${ }^{22}$ In the current study, tissue oxygenation index was $32 \%$ to $53 \%$ before CPB (baseline), whereas $\mathrm{SvO}_{2}$ was usually $70 \%$ to $80 \%$ and sagittal sinus saturation was $40 \%{ }^{4}$ Tissue oxygenation index increased up to approximately $70 \%$ in all groups during the cooling phase except in 2 nonsurviving animals that showed inadequate increases of tissue oxygenation index, suggesting poor brain oxygenation irrespective of hypothermia or hemodilution. Tissue oxygenation index may therefore reflect brain oxygenation state accurately even under conditions of deep hypothermia, hemodilution, and $\mathrm{pH}$ shifts.

We have previously reported both laboratory and clinical studies that suggest that the $\mathrm{pH}$-stat strategy is preferable to the alpha-stat strategy. ${ }^{23-26}$ Therefore, we used the $\mathrm{pH}$-stat strategy for all groups in this study. The pH-stat strategy (addition of carbon dioxide to the oxygenator gas mixture) increases cerebral blood flow, thereby improving cooling of the brain and increasing oxygen delivery before HCA. The oxyhemoglobin dissociation curve is shifted to the right, improving oxygen delivery, and cerebral metabolic rate is depressed during HCA, thereby reducing oxygen requirements. Nevertheless, the alternative, alpha-stat strategy, continues to be widely applied. Its 
widespread use limits the relevance of the findings of our study for many centers continuing to use the alpha-stat strategy. Therefore, in future studies we plan to examine the influence of hematocrit value in the setting of the alpha-stat strategy, particularly under HCA. We believe there will be an additive interaction such that a combination of alpha-stat and lower hematocrit value will be a particularly damaging combination and will shorten the time to $\mathrm{HbO}_{2}$ nadir. We are hopeful that these further studies will further validate the $\mathrm{HbO}_{2}$ nadir time as a useful predictor of safe duration of HCA. In addition, we plan to undertake further studies using continuous CPB in which we will explore whether this parameter might also be useful in defining safe levels of hemodilution and safe low flow states such as are very widely applied in surgery for correction of congenital heart anomalies.

We are grateful to Madeleine Höckenström, MD, AB Sangtec Medical, Sweden, for technical support. David Zurakowski, PhD, from the Department of Biostatistics at Children's Hospital, Boston, provided us valuable advice regarding the statistical analysis. We also thank Hamamatsu Photonics K.K., Hamamatsu City, Japan, for their support.

\section{References}

1. Newburger JW, Jonas RA, Wernovsky G, Wypij D, Hickey PR, Kuban $\mathrm{KC}$, et al. A comparison of the perioperative neurologic effects of hypothermic circulatory arrest versus low-flow cardiopulmonary bypass in infant heart surgery. N Engl J Med. 1993;29:1057-64.

2. Bellinger DC, Wypij D, Kuban KC, Rappaport LA, Hickey PR, Wernovsky G, et al. Developmental and neurological status of children at 4 years of age after heart surgery with hypothermic circulatory arrest or low-flow cardiopulmonary bypass. Circulation. 1999; 100:526-32.

3. Edmonds HL Jr, Rodriguez RA, Audenaert SM, Austin EH 3rd, Pollock SB Jr, Ganzel BL. The role of neuromonitoring in cardiovascular surgery. J Cardiothorac Vasc Anesth. 1996;10:15-23.

4. McDaniel LB, Zwischenberger JB, Vertrees RA, Nutt L, Uchida T, Nguyen T, et al. Mixed venous oxygen saturation during cardiopulmonary bypass poorly predicts regional venous saturation. Anesth Analg. 1995;80:466-72.

5. Kunihara T, Myojin K, Matano J, Tamura M. Clinical study on measurement of cerebral metabolism and oxygenation during cardio-pulmonary bypass by near-infrared spectrophotometry. Nippon Kyobu Geka Gakkai Zasshi. 1995;43:1107-14.

6. Nomura F, Naruse H, du Plessis A, Hiramatsu T, Forbess J, Holtzman $\mathrm{D}$, et al. Cerebral oxygenation measured by near infrared spectroscopy during cardiopulmonary bypass and deep hypothermic circulatory arrest in piglets. Pediatr Res. 1996;40:790-6.

7. Wahr JA, Tremper KK, Samra S, Delpy DT. Near-infrared spectroscopy: theory and applications. J Cardiothorac Vasc Anesth. 1996;10:406-18.

8. Kurth CD, Uher B. Cerebral hemoglobin and optical pathlength influence near-infrared spectroscopy measurement of cerebral oxygen saturation. Anesth Analg. 1997;84:1297-305.

8a. Sakamoto T, Jonas RA, Stock UA, Hatsuoka S, Cope M, Springett RJ, et al. Utility and limitations of near-infrared spectroscopy during car- diopulmonary bypass in a piglet model. Pediatr Res. 2001;49:770-6.

9. Shin'oka T, Shum-Tim D, Jonas RA, Lidov HG, Laussen PC, Miura T, et al. Higher hematocrit improves cerebral outcome after deep hypothermic circulatory arrest. J Thorac Cardiovasc Surg. 1996;112:1610-20.

10. Forbess JM, Ibla JC, Lidov HG, Cioffi MA, Hiramatsu T, Laussen P, et al. University of Wisconsin cerebroplegia in a piglet survival model of circulatory arrest. Ann Thorac Surg. 1995;60(6 Suppl):S494-500.

11. Westaby S, Saatvedt K, White S, Katsumata T, van Oeveren W, Bhatnagar NK, et al. Is there a relationship between serum S-100 $\beta$ protein and neuropsychologic dysfunction after cardiopulmonary bypass? J Thorac Cardiovasc Surg. 2000;119:132-7.

12. Miura T, Laussen P, Lidov HG, DuPlessis A, Shin'oka T, Jonas RA. Intermittent whole-body perfusion with "somatoplegia" versus blood perfusate to extend duration of circulatory arrest. Circulation. 1996;94(9 Suppl):II-56-62.

13. McCullough JN, Zhang N, Reich DL, Juvonen TS, Klein JJ, Spielvogel D, et al. Cerebral metabolic suppression during hypothermic circulatory arrest in humans. Ann Thorac Surg. 1999;67:1895-9.

14. Shin'oka T, Shum-Tim D, Laussen PC, Zinkovsky SM, Lidov HG, du Plessis A, et al. Effects of oncotic pressure and hematocrit on outcome after hypothermic circulatory arrest. Ann Thorac Surg. 1998;65:155-64.

15. Connolly JE, Roy A, Guernsey JM, Stemmer EA. Bloodless surgery by means of profound hypothermia and circulatory arrest: effect on brain and heart. Ann Surg. 1965;162:724-37.

16. Perna AM, Gardner TJ, Tabaddor K, Brawley RK, Gott VL. Cerebral metabolism and blood flow after circulatory arrest during deep hypothermia. Ann Surg. 1973;178:95-101.

17. Wells FC, Coghill S, Caplan HL, Lincoln C. Duration of circulatory arrest does influence the psychological development of children after cardiac operation in early life. J Thorac Cardiovasc Surg. 1983;86:823-31.

18. O'Connor JV, Wilding T, Farmer P, Sher J, Ergin MA, Griepp RB. The protective effect of profound hypothermia on the canine central nervous system during one hour of circulatory arrest. Ann Thorac Surg. 1986;41:255-9.

19. Fessatidis IT, Thomas VL, Shore DF, Sedgwick ME, Hunt RH, Weller RO. Brain damage after profoundly hypothermic circulatory arrest: correlations between neurophysiologic and neuropathologic findings-an experimental study in vertebrates. $J$ Thorac Cardiovasc Surg. 1993;106:32-41.

20. Niwa H, Nara M, Kimura T, Chiba Y, Ihaya A, Morioka K, et al. Prolongation of total permissible circulatory arrest duration by deep hypothermic intermittent circulatory arrest. J Thorac Cardiovasc Surg. 1998;116:163-70.

21. Shin'oka T, Nollert G, Shum-Tim D, du Plessis A, Jonas RA. Utility of near-infrared spectroscopic measurements during deep hypothermic circulatory arrest. Ann Thorac Surg. 2000;69:578-83.

22. Suzuki S, Takasaki S, Ozaki T, Kobayashi Y. A tissue oxygenation monitor using NIR spatially resolved spectroscopy. Proc SPIE. 1999;3597:582-92.

23. Aoki M, Nomura F, Stromski ME, Tsuji MK, Fackler JC, Hickey PR, et al. Effects of $\mathrm{pH}$ on brain energetics after hypothermic circulatory arrest. Ann Thorac Surg. 1993;55:1093-103.

24. Hiramatsu T, Miura T, Forbess JM, du Plessis A, Aoki M, Nomura F, et al. $\mathrm{pH}$ strategies and cerebral energetics before and after circulatory arrest. J Thorac Cardiovasc Surg. 1995;109:948-57.

25. Jonas RA, Bellinger DC, Rappaport LA, Wernovsky G, Hickey PR, Farrell DM, et al. Relation of pH strategy and developmental outcome after hypothermic circulatory arrest. J Thorac Cardiovasc Surg. 1993;106:362-8.

26. du Plessis AJ, Jonas RA, Wypij D, Hickey PR, Riviello J, Wessel DL, et al. Perioperative effects of alpha-stat versus $\mathrm{pH}$-stat strategies for deep hypothermic cardiopulmonary bypass in infants. $J$ Thorac Cardiovasc Surg. 1997;114:991-1000. 